\title{
Allelopathy of the raphidophyte Heterosigma akashiwo against the dinoflagellate Akashiwo sanguinea is mediated via allelochemicals and cell contact
}

\author{
Xuchun Qiu1 ${ }^{1}$, Yasuhiro Yamasaki ${ }^{2}$, Yohei Shimasaki ${ }^{1, *}$, Hiroaki Gunjikake ${ }^{1}$, \\ Masato Honda ${ }^{1}$, Mayumi Kawaguchi ${ }^{1}$, Tadashi Matsubara ${ }^{3}$, Sou Nagasoe ${ }^{4}$, \\ Takuya Etoh $^{5}$, Shigeaki Matsui ${ }^{5}$, Tsuneo Honjo ${ }^{6}$, Yuji Oshima ${ }^{1}$ \\ ${ }^{1}$ Laboratory of Marine Environmental Science, Faculty of Agriculture, Kyushu University, Hakozaki 6-10-1, Higashi-ku, \\ Fukuoka 812-8581, Japan \\ ${ }^{2}$ National Fisheries University, 2-7-1 Nagata-Honmachi, Shimonoseki 759-6595, Japan \\ ${ }^{3}$ Saga Prefectural Ariake Fisheries Research and Development Center, 2753-2 Nagata, Ashikari-cho, Ogi, Saga 849-0313, Japan \\ ${ }^{4}$ Miyazu Station, National Center for Stock Enhancement, Fisheries Research Agency, 1721 Oda Shukuno, Miyazu, \\ Kyoto 626-0052, Japan \\ ${ }^{5}$ Fukuoka Fisheries and Marine Technology Research Center, 1141-1 Imazu, Nishi-ku, Fukuoka 819-0165, Japan \\ ${ }^{6}$ Seto Inland Sea Regional Research Center, Kagawa University, Saiwaichou 1-1, Takamatsu, Kagawa 760-8521, Japan
}

\begin{abstract}
Growth interactions between the raphidophyte Heterosigma akashiwo and the dinoflagellate Akashiwo sanguinea were examined by using bi-algal culture experiments under axenic conditions. There was a lethal effect of $H$. akashiwo (initial cell density: $1 \times 10^{2}$ or $1 \times$ $10^{4} \mathrm{cells} \mathrm{ml}^{-1}$ ) on $A$. sanguinea at an initial cell density of $1 \times 10^{2}$ cells ml$^{-1}$. Growth of both species was suppressed concurrently when initial cell densities of $H$. akashiwo and $A$. sanguinea were $1 \times 10^{2}$ and $2 \times 10^{3} \mathrm{cells} \mathrm{ml}^{-1}$, respectively. A mathematical model was used to simulate growth and interactions in bi-algal cultures. The model predicted that $H$. akashiwo would outcompete A. sanguinea over time. A cell-free enriched filtrate prepared from dense culture of $H$. akashiwo reduced both maximum growth rate and maximum yield of $A$. sanguinea. A filtrate of $A$. sanguinea prepared in the same manner only reduced maximum yield of $H$. akashiwo but did not affect its maximum growth rate. Growth of $A$. sanguinea in bi-algal cultures under contact conditions was significantly lower than that in mono-algal culture and in bi-algal cultures under noncontact conditions. Morphologically abnormal A. sanguinea cells occurred at high frequency only when $A$. sanguinea was cultured together with $H$. akashiwo under direct cell contact condition. Moreover, growth inhibition and formation of morphologically abnormal cells of $A$. sanguinea were induced in a concentration-dependent manner by allelochemicals (including allelochemical polysaccharide-protein complexes) produced by $H$. akashiwo. These results suggest that growth inhibition effects, via allelochemicals and direct cell contact by Heterosigma akashiwo, influence bloom formation of Akashiwo sanguinea in the field.
\end{abstract}

KEY WORDS: Heterosigma akashiwo $\cdot$ Akashiwo sanguinea $\cdot$ Allelopathy Polysaccharideprotein complex $\cdot$ Cell contact $\cdot$ Growth interaction $\cdot$ Growth simulation

\section{INTRODUCTION}

The dinoflagellate Akashiwo sanguinea (Hirasaka) G. Hansen et Moestrup (synonyms: Gymnodinium sanguineum Hirasaka [Daugbjerg et al., 2000], G. nelsonii Martin [Martin, 1929], G. splendens Lebour [Lebour, 1925]) is a harmful algal bloom (HAB) species which has been observed in many coastal 
waters around the globe (Domingos \& Menezes 1998, Gómez \& Boicenco 2004, Kim et al. 2004, Lu \& Hodgkiss 2004, Rines et al. 2010). A. sanguinea has been associated with mortality in abalone larvae and spat, and in seabirds (Botes et al. 2003, Jessup et al. 2009), and is also suspected to cause discoloration of the edible laver 'nori' in the Ariake Sea, Japan (Nakamura \& Hirata 2006, Tsutsumi 2006).

Several physiological and ecological studies (Doucette \& Harrison 1991, Voltolina 1993, Silva \& Faust 1995, Kudela et al. 2008) have attempted to clarify the mechanisms of bloom formation by Akashiwo sanguinea. Matsubara et al. (2007) examined growth characteristics of $A$. sanguinea and suggested that this species has the potential to form blooms during early summer in coastal waters of Japan. However, during spring and early summer, which may be suitable for bloom formation of $A$. sanguinea, the phytoplankton community in the Ariake Sea is frequently dominated by alternative blooms of the raphidophyte Heterosigma akashiwo (Hada) Hada ex Hara et Chihara and some certain diatoms, whereas A. sanguinea rarely bloom although its vegetative cells have been detected at very low cell density (Tezaki et al. 2005, Tsutsumi 2006, Yamatogi et al. 2006). From the results of field observations over $3 \mathrm{yr}$, the phytoplankton community structure of the Ariake Sea in autumn was characterized by persistent dominance of $A$. sanguinea (Nakamura \& Hirata 2006).

In nature, biological, physical or chemical factors are involved in the bloom formation of phytoplankton. Grazing impact (Johansson \& Coats 2002, Smayda 2008) and interspecific growth interactions (Poulson et al. 2009) are major factors affecting the population of phytoplankton. Nakamura \& Hirata (2006) reported that Akashiwo sanguinea has the ability to escape from grazing pressure and light limitation and could dominate in the Ariake Sea. Similarly, it has been suggested that the predation pressure of microbial loop components or macrograzers is not a significant factor in bloom termination of Heterosigma akashiwo because of the broad spectrum allelopathy of this species (Smayda 1998). Therefore, the discrepancy between the laboratory and field observations suggests that interspecific interactions with $H$. akashiwo may affect the survival and growth of $A$. sanguinea in the field during spring and early summer.

Interspecific interactions caused by allelopathy or cell contact have been discussed as a phenomenon affecting phytoplankton bloom formation. Legrand et al. (2003) and Granéli \& Hansen (2006) reviewed allelopathy in phytoplankton, and Uchida (2001) reported the role of cell contact in some dinoflagellate species. More recently, Prince et al. (2008) reported that the dinoflagellate Karenia brevis exudes allelochemicals during blooms, and may achieve nearly monospecific blooms by growth suppression or death through lowering the photosynthetic efficiency and increasing the membrane permeability of their competitors. In addition, Paul et al. (2009) investigated the role of allelopathic interactions between diatom species, and indicated that chemical cross-talk between the species might lead to physiological responses and changed cell abundances. Furthermore, Tang \& Gobler (2010) raised the possibility that toxicity to fish and shellfish larvae, and allelopathic effects by the dinoflagellate Cochlodinium polykrikoides were caused by the same agents such as reactive oxygen species (ROS)like chemicals.

As for other species also, these interspecific interactions have been reported to affect bloom formation by Akashiwo sanguinea (Kayser 1979, Yamasaki et al. 2007a, Matsubara et al. 2008). In spring and summer, allelopathy of centric diatom blooms is an important factor that inhibits the growth of $A$. sanguinea (Matsubara et al. 2008). Recently, Yamasaki et al. (2009) reported that allelopathic polysaccharide-protein complexes (APPCs) produced by Heterosigma akashiwo inhibited the growth of the diatom Skeletonema costatum, as the APPCs concentrations in the water exceeded the threshold of allelopathic potential. Thus, it is reasonable to propose that the allelopathic effect of $H$. akashiwo blooms during spring and early summer plays an important role in bloom formation of $A$. sanguinea.

In this study, we conducted bi-algal culture experiments under axenic conditions using several initial cell density combinations of Heterosigma akashiwo and Akashiwo sanguinea. We also simulated the growth of either species in bi-algal cultures using a mathematical model to quantify growth relationships between them. In addition, we examined allelopathic interactions between $H$. akashiwo and A. sanguinea by way of growth experiments using culture filtrates. Furthermore, we examined effects of direct cell contact with $H$. akashiwo on the growth and cell morphology of $A$. sanguinea through bi-algal culture experiments under noncontact and contact conditions. Finally, we tested inhibitory effects of allelochemicals fractions (including APPCs) produced by $H$. akashiwo on A. sanguinea growth. 


\section{MATERIALS AND METHODS}

\section{Algal species and culture conditions}

Axenic strains of Heterosigma akashiwo (NIES10) and Skeletonema sp. (NIES-324) were obtained from the National Institute of Environmental Studies (NIES, Japan). Akashiwo sanguinea used in this study was isolated in November 2002 from Hakozaki Harbor in Hakada Bay, Japan (Matsubara et al. 2007). Both strains were verified as axenic using 4',6-diamidino-2-phenylindole (DAPI) staining for testing on bacterial contamination (Porter \& Feig 1980). Axenic cultures were maintained in $70 \mathrm{ml}$ sterile flasks (Nunc, Thermo Fisher Scientific) containing $20 \mathrm{ml}$ of modified sea water medium (modified SWM-3, Yamasaki et al. 2007b) at a salinity of 30 . The modified SWM-3 medium contained $0.04 \% \quad(\mathrm{w} / \mathrm{v})$ of tris(hydroxymethyl)aminomethane (Wako Pure Chemical Industries) to buffer $\mathrm{pH}$ during the experiments, and the medium was autoclaved before use $\left(121^{\circ} \mathrm{C}, 15 \mathrm{~min}\right)$. All flasks were kept in an incubator (FLI-160, Tokyo Rikakikai) at $25^{\circ} \mathrm{C}$ under $250 \pm 8 \mu \mathrm{mol}$ photons $\mathrm{m}^{-2} \mathrm{~s}^{-1}$ of cool-white fluorescent illumination at a 12:12 h light:dark cycle. Irradiance in the incubator was measured using a Quantum Scalar Laboratory Irradiance Sensor (QSL-2101, Biospherical Instruments).

\section{Bi-algal culture experiments}

Bi-algal culture experiments were conducted in $70 \mathrm{ml}$ sterile flasks (Nunc) containing $20 \mathrm{ml}$ of the modified SWM-3 medium. Heterosigma akashiwo and Akashiwo sanguinea cells in early stationary phase were inoculated at cell densities of $1 \times 10^{2}$, $2 \times 10^{3}$ and $1 \times 10^{4}$ cells ml $^{-1}$ (see Table 1 ). In addition, either species was inoculated at the same initial cell densities in mono-algal culture as controls. For each treatment, 3 replicate flasks were prepared. All flasks were gently mixed by hand twice a day and randomly rearranged to minimize the effects of light or temperature heterogeneity in the incubator. Every other day, the $\mathrm{pH}$ of each culture medium was measured (B-212 pH meter), and $100 \mu \mathrm{l}$ subsamples were taken for counting the cells under a light microscope. When cell densities exceeded $2 \times 10^{4}$ cells ml ${ }^{-1}$, subsamples were diluted by a factor of 10 to 20 with fresh modified SWM-3 medium before counting.

\section{Macronutrient analysis}

At the end of the bi-algal experiments, $10 \mathrm{ml}$ of each culture was gravity-filtered through glass microfibre filters (GF/C, Whatman). Filtrates were then passed through $0.22 \mu \mathrm{m}$ syringe filters and frozen at $-80^{\circ} \mathrm{C}$ until analysis. Nitrogen $\left(\mathrm{NO}_{2}{ }^{-}+\mathrm{NO}_{3}{ }^{-}\right)$and phosphorus $\left(\mathrm{PO}_{4}{ }^{3-}\right)$ were measured using an auto analyzer (TRACCS 800, Bran \& Luebbe) after samples were diluted $10 \times$ with Milli-Q water (Millipore).

\section{Simulation of growth in bi-algal cultures}

To model the cell growth in bi-algal cultures of Heterosigma akashiwo and Akashiwo sanguinea, we adopted the growth simulation of Uchida et al. (1999). The following equations were used for the simulation:

$$
\begin{aligned}
& \mathrm{d} x / \mathrm{d} t=r_{X} x\left(1-x / K_{X}\right)-A x y=r_{X} x\left[1-(x+a y) / K_{X}\right] \\
& \mathrm{d} y / \mathrm{d} t=r_{Y} y\left(1-y / K_{Y}\right)-B x y=r_{Y} y\left[1-(b x+y) / K_{Y}\right]
\end{aligned}
$$

Here, $x$ and $y$ are the cell densities of the 2 species in bi-algal culture, $r_{X}$ and $K_{X}$ are the growth rate and carrying capacity of $A$. sanguinea in mono-algal culture, respectively, and $r_{Y}$ and $K_{Y}$ are the corresponding parameters for $H$. akashiwo. Parameter $A$ measures the degree of inhibition of $A$. sanguinea by $H$. akashiwo, and $B$ measures the inhibition of $H$. akashiwo by $A$. sanguinea. If we set $A=a r_{x} / K_{x}$ and $B=b r_{Y} / K_{Y}$ Eqs. (1) \& (2) become the same as the formula for the growth of populations competing with each other for limited resources (Iwasa 1998). Parameters $a$ and $b$ are nondimensional and measure the degree of inhibition by the other species compared to self-interference. When each species is cultured in mono-algal culture, we can set $a=b=0$.

The logistic parameters $\left(r_{x}, r_{y}, K_{X}, K_{Y}\right)$ were estimated by Eqs. (1) \& (2) using the mono-algal culture data from bi-algal cultures when Akashiwo sanguinea and Heterosigma akashiwo cells were inoculated to a initial density of $1 \times 10^{2}$ cells ml${ }^{-1}$, respectively $(\mathrm{n}=3)$. Next, the parameters $a$ and $b$ were calculated directly from Eqs. (1) \& (2) using the data from bi-algal culture experiments. Precise estimation of $a$ and $b$ was carried out using the Marquardt method (Marquardt 1963), with the most appropriate values of $a$ and $b$ determined by when the difference between the squared values of observed cell density and theoretical cell density reached a minimum. Then, the parameters $A$ and $B$ were calculated from the equations $A=a r_{X} / K_{x}$ and $B=b r_{y} / K_{y \prime}$ respectively. 


\section{Effect of culture filtrates on growth of each species}

As soon as cell densities (cells $\mathrm{ml}^{-1}$ ) reached $5 \times 10^{5}$ for Heterosigma akashiwo, or $1.5 \times 10^{4}$ for Akashiwo sanguinea, these cultures were passed through glass microfibre filters (GF/C). To compensate nutrients consumed by algal growth in filtrates, the same amount of nutrients as original modified SWM-3 medium were added to either filtrate (re-enriched) and the final nutrient concentrations of filtrates were expected to be between 100 to $200 \%$ of the original modified SWM-3 medium. Thus, both species were cultured alone in modified SWM-3 medium with nutrient concentration elevated to $200 \%$ of the original medium concentration (re-enriched medium) to evaluate any nutrient inhibitory effect in re-enriched filtrates. As a control, both species were cultured alone in modified SWM-3 medium (original medium). The $\mathrm{pH}$ of each filtrate was adjusted to 7.8-8.0 with $2 \mathrm{~N} \mathrm{HCl}$; subsequently, all media (filtrates and controls) were passed through $0.22 \mu \mathrm{m}$ syringe filters (Millipore).

For the growth experiment in culture filtrates, Heterosigma akashiwo and Akashiwo sanguinea were cultured separately in $8 \mathrm{ml}$ sterile culture tubes (Evergreen Scientific) containing $5 \mathrm{ml}$ of a prepared test media. Initial cell density of either species was $1 \times 10^{2}$ cells $\mathrm{ml}^{-1}$, with 4 replicate tubes for each treatment. Relative cell abundances were measured daily by in vivo fluorescence (10-AU-005-CE fluorometer, Turner Designs), and growth rates during the exponential growth phase were calculated after Guillard (1973).

\section{Bi-algal culture experiments under non-contact and contact conditions}

The experimental design of separating 2 algae cultures by a dialysis membrane has been used to differentiate between allelopathy due to allelochemical molecules and cell contact effect (e.g. Yamasaki et al. 2007a,b, Tang \& Gobler 2010), and to monitor the physiological response of the interactions between 2 diatom species approached with metabolic profiling (Paul et al. 2009). For our experiment, we used plates with 6 wells and inserted cell culture plates (BD353091, Becton-Dickinson), as described in Yamasaki et al. (2007b). The insert plates have a membrane filter (pore size $3.0 \mu \mathrm{m}$ ) on the bottom. Akashiwo sanguinea cells in early stationary phase were suspended in modified SWM-3 medium at a density of 267 cells $\mathrm{ml}^{-1}$, and $3 \mathrm{ml}$ of cell suspension were inoc- ulated into each inner chamber (final density $1 \times 10^{2}$ cells $\mathrm{ml}^{-1}$ ). Heterosigma akashiwo cells in early stationary phase were suspended in modified SWM-3 medium at 2 cell densities (160 and $1.6 \times 10^{4}$ cells $\mathrm{ml}^{-1)}$, and $5 \mathrm{ml}$ were inoculated into the outer chambers of the well plates (final densities $1 \times 10^{2}$ and $1 \times$ $10^{4}$ cells $\mathrm{ml}^{-1}$ ). For comparison, $H$. akashiwo and $A$. sanguinea were cultured together in the well plates without the insert plates in the same combinations just described, allowing direct cell contact. As a control, A. sanguinea (final cell density $1 \times 10^{2}$ cells ml $^{-1}$ ) was cultured in fresh modified SWM-3 medium. For each treatment, 3 replicate wells were used. The morphology of A. sanguinea cells was observed 4 times per day using an inverted microscope. On Day 8 after incubation, the numbers of morphologically normal and abnormal cells of $A$. sanguinea in each well were counted microscopically (three $100 \mu \mathrm{l}$ subsamples per well).

\section{Growth inhibitory effect of allelochemicals produced by Heterosigma akashiwo}

The fraction containing allelochemicals was prepared following Yamasaki et al. (2009). H. akashiwo was inoculated at a density of $1 \times 10^{2}$ cells ml ${ }^{-1}$ into $100 \mathrm{ml}$ glass flasks $(\mathrm{n}=3$ ) containing $50 \mathrm{ml}$ of modified SWM-3 medium. After 20 d, $50 \mathrm{ml}$ samples from each of the 3 culture flasks (density $5.6 \times 10^{5}$ cells $\mathrm{ml}^{-1}$ ) were combined to make up a total volume of $150 \mathrm{ml}$, which was gravity filtered through a membrane filter (5.0 $\mu \mathrm{m}$ pore size, Millipore). The filtrate was passed through another membrane filter (0.45 $\mu \mathrm{m}$ pore size, Millipore). Then, the filtrate was dialysed against deionized water for $3 \mathrm{~d}$ at $4{ }^{\circ} \mathrm{C}$ using dialysis membranes with a 3500 Da molecular weight cut-off (Spectrum Laboratories). After the dialysis, the inner solution was frozen at $-80^{\circ} \mathrm{C}$ and lyophilized with a Free Zone 2.5 freeze-drying apparatus (Labconco). A portion of the lyophilized allelochemicals obtained from filtrates of $H$. akashiwo cultures was dissolved in $10 \mathrm{ml}$ of modified SWM-3 medium (final concentration $200 \mu \mathrm{g} \mathrm{ml}^{-1}$ ), and passed through a $0.22 \mu \mathrm{m}$ syringe filter (Millipore). To confirm whether the sample contained APPCs or not, its inhibitory effect was tested on Skeletonema sp. (Fig. 1A). In addition, the sample was analysed by SDS-PAGE on $5 \%$ gels according to Laemmli (1970). After electrophoresis, the extremely large molecular sizes (i.e. APPCs) of the allelochemicals, in addition to other minor bands, were visualized by silver staining the SDS-PAGE gel (Fig. 1B). Thus, it was consid- 

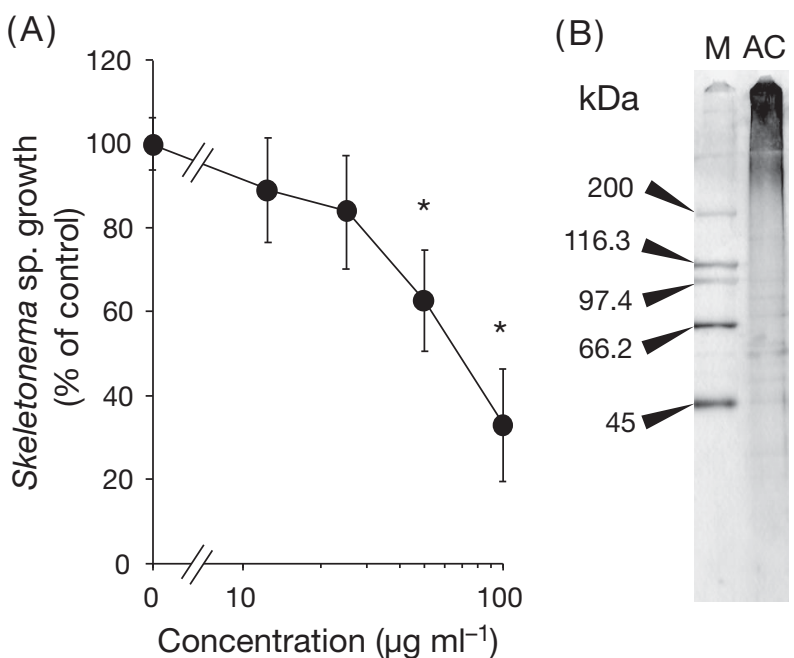

Fig. 1. Heterosigma akashiwo. Allelochemicals including allelophobic polysaccharide-protein complexes prepared from culture medium filtrates. (A) Concentration-dependent growth inhibition of Skeletonema sp. by H. akashiwo allelochemicals. (B) SDS-PAGE of the allelochemicals fraction using $5 \%$ polyacrylamide gel. After electrophoresis, the gel was silver stained. Lane M: molecular mass standard markers. Lane AC: the allelochemicals fraction prepared from the culture. *: significant difference between growth of Skeletonema sp. exposed to allelo-chemicals and controls $(\mathrm{p}<0.01)$

ered proven that the sample prepared from $H$. akashiwo filtrate contained APPCs (along with other substances).

Akashiwo sanguinea cultures in the late exponential growth phase were diluted to $1 \times 10^{3}$ cells ml $^{-1}$ with modified SWM-3 medium. Of this cell supension, $100 \mu \mathrm{l}$ were added to $900 \mu \mathrm{l}$ of each sample solution including allelochemicals of different concentrations to be tested in 48-well plates (initial cell density $1 \times 10^{2}$ cells ml ${ }^{-1}$ ). Final concentrations of the allelochemicals fraction in bioassays were 12.5, 25, 50, 100, and $200 \mu \mathrm{g} \mathrm{ml}^{-1}$. Each bioassay had 3 replicates. As a control, A. sanguinea was cultured in modified SWM-3 medium without the addition of any sample solution. After incubation for $4 \mathrm{~d}$, the cells in each of five $10 \mu \mathrm{l}$ subsamples from each well were counted under the microscope.

\section{Statistical analyses}

The experimental data were checked for homogeneity of variance across treatments with Levene's test. When variances were homogeneous, the differences in cell densities among treatments (see Fig. 5A) and proportions of morphologically abnormal cells (see Table 3) of Akashiwo sanguinea were tested using 1-way analysis of variance (1-way ANOVA) followed by Tukey test; and the differences in the maximum growth rates and maximum yields between treatments and control (see Fig. 4A,D) were tested using 1-way ANOVA followed by Dunnett's test. When data were heteroscedastic, the differences in cell densities of $A$. sanguinea between treatments and control (see Figs. 1A \& 6A) were tested using a non-parametric Mann-Whitney $U$-test. These statistical analyses were conducted by using the Statistical Package for the Social Sciences software (SPSS 13.0; SPSS).

\section{RESULTS}

\section{Bi-algal culture experiment}

With initial cell densities of $1 \times 10^{2}$ cells ml $^{-1}$ for both Heterosigma akashiwo and Akashiwo sanguinea (Fig. 2A), the growth of $A$. sanguinea was suppressed from Day 4 onwards. Cell density of $A$. sanguinea started to decline at Day 8 when $H$. akashiwo reached the stationary phase, and A. sanguinea had almost disappeared by Day 14 at the end of the experiment. In contrast, the growth of $H$. akashiwo in both bi- and mono-algal cultures was almost identical. The $\mathrm{pH}$ of the culture medium at these initial cell densities ranged from 7.82 to 8.72 (Table 1).

When initial cell densities of Heterosigma akashiwo and Akashiwo sanguinea were $1 \times 10^{4}$ and $1 \times$ $10^{2}$ cells $\mathrm{ml}^{-1}$, respectively (Fig. 2B), there was no growth of $A$. sanguinea and this species almost disappeared on Day 8 when $H$. akashiwo reached the stationary phase, while the growth of $H$. akashiwo in both bi- and mono-algal cultures was virtually the same. The $\mathrm{pH}$ of the culture medium at these initial cell densities ranged from 7.92 to 8.72 (Table 1).

When initial cell densities of Heterosigma akashiwo and Akashiwo sanguinea were $1 \times 10^{2}$ and $2 \times$ $10^{3} \mathrm{cells} \mathrm{ml}^{-1}$, respectively (Fig. 2C), the growth of $A$. sanguinea was suppressed from Day 8 onwards, after which its average maximum cell density was $\sim 24 \%$ of that in mono-algal cultures. On the other hand, the growth rate of $H$. akashiwo was lowered from Day 4 onwards; however, the average cell density of $H$. akashiwo in bi-algal culture increased and reached at same level of mono-algal culture on Day 12. The average maximum cell density of $H$. akashiwo was $\sim 48 \%$ of that in mono-algal culture. The $\mathrm{pH}$ of culture medium at these initial cell densities ranged from 7.90 to 8.59 (Table 1). 

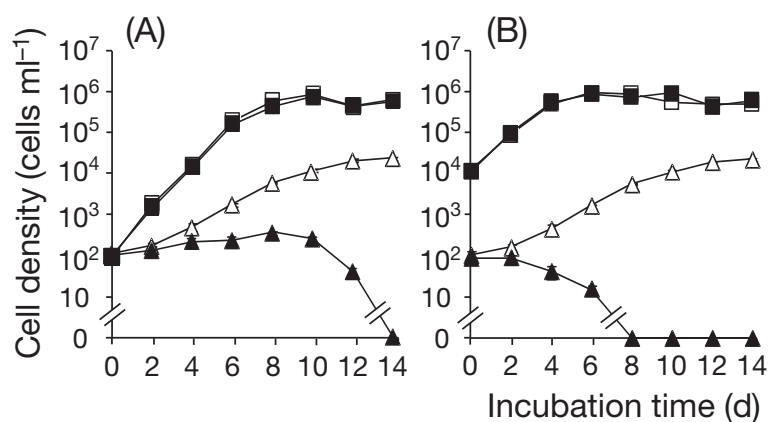

(C)

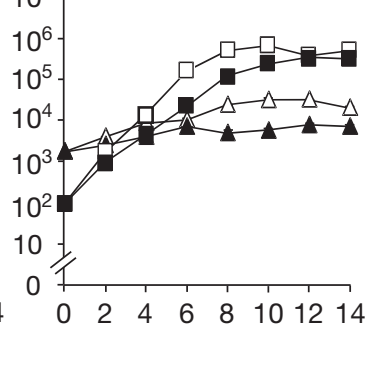

Fig. 2. Akashiwo sanguinea and Heterosigma akashiwo. Growth of $A$. sanguinea when cultured alone $(\Delta)$ or together with $H$. akashiwo $(\mathbf{\Delta})$, and of $H$. akashiwo when cultured alone ( $\square$ ) or together with $A$. sanguinea (ם). Initial cell densities (cells ml ${ }^{-1}$ ) of $A$. sanguinea: $1 \times 10^{2}(\mathrm{~A}, \mathrm{~B})$ or $2 \times 10^{3}(\mathrm{C})$, and of $H$. akashiwo: $1 \times 10^{2}(\mathrm{~A}, \mathrm{C})$ or $1 \times 10^{4}(\mathrm{~B})$. Means $\pm \mathrm{SD}(\mathrm{n}=3)$. Error bars are small and mostly obscured by the symbols

Table 1. Heterosigma akashiwo and Akashiwo sanguinea. Initial cell densities, final macronutrient concentrations and pH ranges in culture media during mono- and bi-algal culture experiments with the 2 species. Data are mean $\pm \mathrm{SD}(\mathrm{n}=3$ ). Initial macronutrient concentrations were $1055 \mu \mathrm{mol} \mathrm{l}{ }^{-1}$ for $\mathrm{NO}_{2}{ }^{-}+\mathrm{NO}_{3}{ }^{-}$and $52 \mu \mathrm{mol} \mathrm{l} l^{-1}$ for $\mathrm{PO}_{4}{ }^{3-}$

\begin{tabular}{|c|c|c|c|c|c|}
\hline \multirow[t]{2}{*}{ Species } & \multirow{2}{*}{$\begin{array}{l}\text { Initial cell density } \\
\quad\left(\text { cells } \mathrm{ml}^{-1}\right)\end{array}$} & \multicolumn{2}{|c|}{ Final macronutrient concentrations $\left(\mu \mathrm{mol} \mathrm{l}{ }^{-1}\right)$} & \multicolumn{2}{|c|}{$\mathrm{pH}$ range in culture media } \\
\hline & & $\mathrm{NO}_{2}^{-}+\mathrm{NO}_{3}^{-}$ & $\mathrm{PO}_{4}^{3-}$ & Lowest & Highest \\
\hline \multicolumn{6}{|l|}{ Mono-algal } \\
\hline \multirow[t]{2}{*}{ A. sanguinea } & $1 \times 10^{2}$ & $4.69 \pm 2.06$ & $14.26 \pm 1.18$ & $7.82 \pm 0.04$ & $8.28 \pm 0.01$ \\
\hline & $2 \times 10^{3}$ & $2.89 \pm 1.65$ & $7.75 \pm 0.12$ & $7.82 \pm 0.02$ & $8.62 \pm 0.01$ \\
\hline \multirow[t]{2}{*}{ H. akashiwo } & $1 \times 10^{2}$ & $3.21 \pm 0.99$ & $0.79 \pm 0.14$ & $7.94 \pm 0.01$ & $8.51 \pm 0.01$ \\
\hline & $1 \times 10^{4}$ & $2.75 \pm 0.17$ & $0.53 \pm 0.14$ & $7.93 \pm 0.01$ & $8.64 \pm 0.02$ \\
\hline \multicolumn{6}{|l|}{ Bi-algal } \\
\hline A. sanguinea & $1 \times 10^{2}$ & $2.67 \pm 0.28$ & $1.06 \pm 0.02$ & $7.82 \pm 0.02$ & $8.72 \pm 0.02$ \\
\hline H. akashiwo & $1 \times 10^{2}$ & & & & \\
\hline A. sanguinea & $1 \times 10^{2}$ & $2.51 \pm 0.50$ & $0.77 \pm 0.21$ & $7.92 \pm 0.01$ & $8.72 \pm 0.03$ \\
\hline H. akashiwo & $1 \times 10^{4}$ & & & & \\
\hline A. sanguinea & $2 \times 10^{3}$ & $2.78 \pm 0.67$ & $4.42 \pm 1.07$ & $7.90 \pm 0.07$ & $8.59 \pm 0.06$ \\
\hline H. akashiwo & $1 \times 10^{2}$ & & & & \\
\hline
\end{tabular}

On Day 14, in all cultures nitrogen $\left(\mathrm{NO}_{2}^{-}+\mathrm{NO}_{3}^{-}\right)$ and phosphorus $\left(\mathrm{PO}_{4}{ }^{3-}\right)$ concentrations ranged from 2.5 to $4.7 \mu \mathrm{mol} \mathrm{l} \mathrm{l}^{-1}$ and from 0.5 to $14.3 \mu \mathrm{mol} \mathrm{l}^{-1}$, respectively (Table 1).

\section{Growth simulation of bi-algal cultures}

The values of all parameters of the growth simulation are shown in Table 2. Importantly, growth patterns of Heterosigma akashiwo and Akashiwo sanguinea predicted using these values were similar to those observed in bi-algal culture experiments (Fig. 3). The parameter values in Table 2 were also used to calculate isoclines (where $\mathrm{dx} / \mathrm{d} t=0$ and $\mathrm{d} y / \mathrm{d} t=0)$ and population trajectories of the 2 species under various initial cell densities (Fig. 4). All simulated trajectories pass through 2 of the following 3 stages: (1) cell densities of both $H$. akashiwo and A. sanguinea increase (Fig. 4, area I); (2) cell densities of $H$. akashiwo increase but those of $A$. sanguinea decrease (Fig. 4, area II), and (3) cell densities of both $H$. akashiwo and A. sanguinea decrease (Fig. 4, area III).

Table 2. Akashiwo sanguinea and Heterosigma akashiwo. Estimated parameters for bi-algal model simulation between the 2 species. Parameters $a$ and $b$ are dimensionless. For details and definitions of $A$ and $B$, see 'Simulation of growth in mixed algal cultures' under 'Materials and methods'

\begin{tabular}{|c|c|c|c|c|c|}
\hline \multirow[t]{2}{*}{ Species } & \multirow{2}{*}{$\begin{array}{l}\text { Carrying capacity } \\
\left(K, \text { cells } \mathrm{ml}^{-1}\right)\end{array}$} & \multicolumn{2}{|c|}{ Growth rate $(r)$} & \multicolumn{2}{|c|}{ - Interaction rate } \\
\hline & & (divisions $\mathrm{h}^{-1}$ ) & (divisions $\mathrm{d}^{-1}$ ) & $a / b$ & $A / B\left(\mathrm{ml}\right.$ cells $\left.{ }^{-1} \mathrm{~s}^{-1}\right)$ \\
\hline A. sanguinea & 27299 & 0.023 & 0.547 & 0.209 & $4.9 \times 10^{-11}$ \\
\hline H. akashiwo & 540009 & 0.052 & 1.27 & 18.8 & $5.2 \times 10^{-10}$ \\
\hline
\end{tabular}


Fig. 3. Heterosigma akashiwo (ם) and Akashiwo sanguinea (山). Growth simulation in bi-algal cultures under various combinations of initial cell densities (cells ml ${ }^{-1}$ ). (A) A. sanguinea $1 \times 10^{2}, H$. akashiwo $1 \times 10^{2}$. (B) A. sanguinea $1 \times 10^{2}, H$. akashiwo $1 \times 10^{4}$. (C) A. sanguinea $2 \times 10^{3}, H$. akashiwo $1 \times 10^{2}$. Symbols: actual data from bialgal cultures. Lines: simulated growth curves

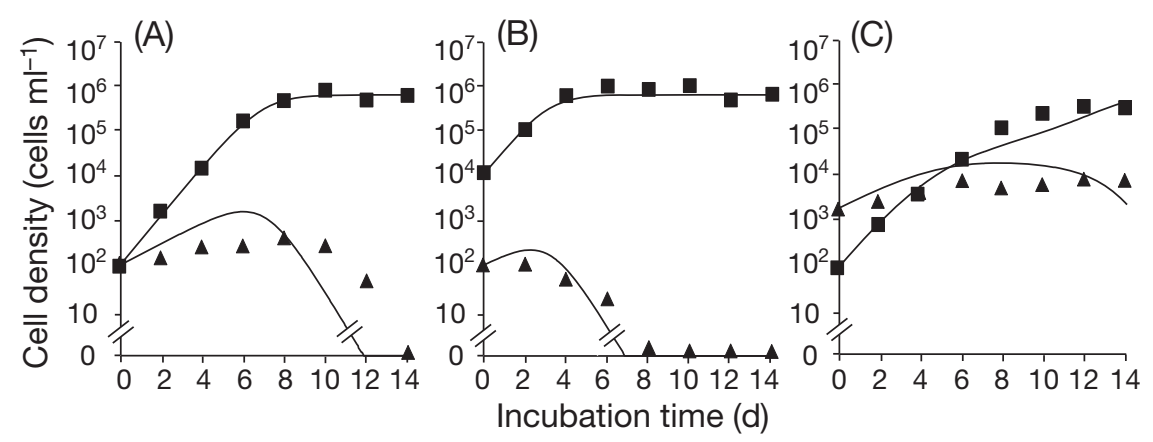

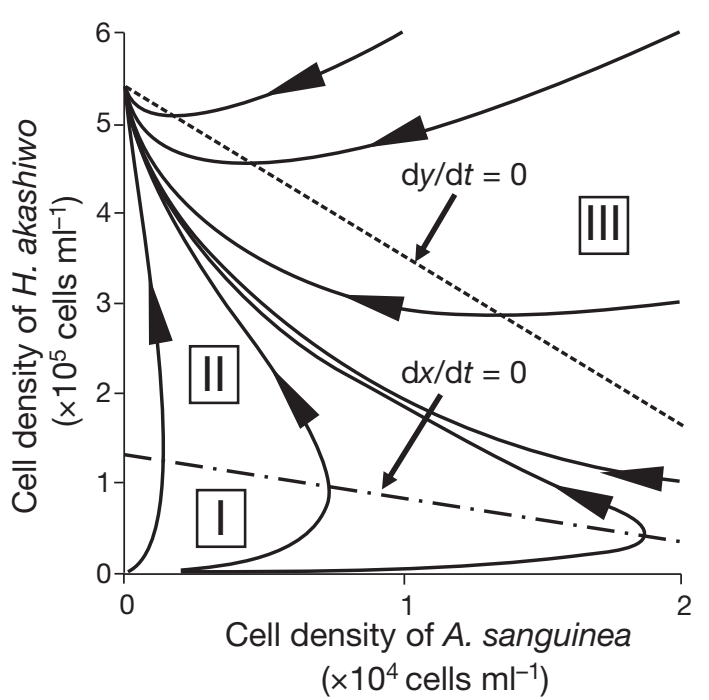

Fig. 4. Heterosigma akashiwo and Akashiwo sanguinea. Simulation of bi-algal cultures showing isoclines (where $\mathrm{d} x / \mathrm{d} t=0$ and $\mathrm{d} y / \mathrm{d} t=0$ ) and trajectories of algal populations cultured under various initial cell densities. Area I: cell densities of both $H$. akashiwo and A. sanguinea increase. Area II: cell densities of $H$. akashiwo increase but those of A. sanguinea decrease. Area III: cell densities of both $H$. akashiwo and $A$. sanguinea decrease. Regardless of the initial cell densities, $H$. akashiwo outcompetes

$$
\text { A. sanguinea over time }
$$

\section{Effect of culture filtrates on phytoplankton growth}

The filtrate from Heterosigma akashiwo cultures significantly decreased the growth of of Akashiwo sanguinea (maximum growth rate to $64 \%$ and maximum yield to $57 \%$ of the control; Dunnett's test, $\mathrm{p}<$ 0.01) (Fig. 5A). In addition, some A. sanguinea cells developed a minor morphological abnormality when they were exposed to filtrate of $H$. akashiwo (compare Fig. 5B,C). The filtrate from $A$. sanguinea cultures decreased the maximum yield of $H$. akashiwo to $73 \%$ of the control (Dunnett's test, p < 0.01), but did not significantly affect its maximum growth rate (Fig. 5D).
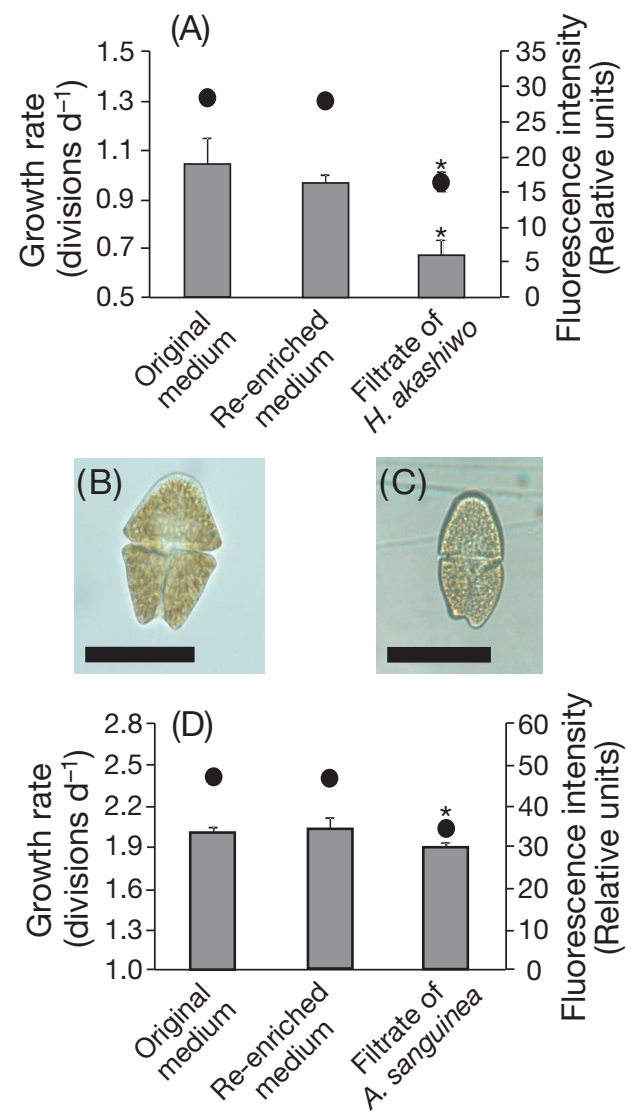

Fig. 5. Heterosigma akashiwo and Akashiwo sanguinea, allelopathic interactions. (A) $H$. akashiwo culture medium filtrate affects growth of $A$. sanguinea. A. sanguinea cell (B) from mono-algal culture (control) and $(\mathrm{C})$ exposed to the reenriched filtrate from $H$. akashiwo culture. Scale bars = $50 \mu \mathrm{m}$. (D) A. sanguinea culture filtrate affects growth of $H$. akashiwo. Means $\pm \mathrm{SD}(\mathrm{n}=3)$. Grey bars: maximum growth rates. : maximum yield of the 2 species as measured by in vivo chlorophyll fluorescence. *: values significantly different $(p<0.01)$ from controls

Maximum growth rates and maximum yields of the 2 species cultured in re-enriched media were similar to that of cells cultured in the original modified SWM-3 medium (Fig. 5), demonstrating that nutrient concentrations in re-enriched filtrates were not responsible for observed inhibitory effects. 


\section{Bi-algal culture experiments under non-contact and contact conditions}

Regardless of differences in initial Heterosigma akashiwo cell density, growth of Akashiwo sanguinea in bi-algal cultures under contact conditions was significantly lower than that in bi-algal cultures under non-contact conditions and in mono-algal culture (Tukey test, $\mathrm{p}<0.05$, Fig. 6A). When the initial cell density of $H$. akashiwo was $1 \times 10^{4}$ cells $\mathrm{ml}^{-1}$, growth of $A$. sanguinea in bi-algal culture under non-contact condition was significantly lower than in mono-algal culture (Tukey test, $\mathrm{p}<0.01$, Fig. 6A).

During our experiments, most Akashiwo sanguinea cells in mono-algal culture and in bi-algal cultures under non-contact conditions maintained the normal cell shape (Fig. 6B,C) as described by Tomas et al. (1997), and the frequency of morphologically abnormal cells was very low during culture period. On Day 8 there was no significant difference in the proportion of morphologically abnormal cells
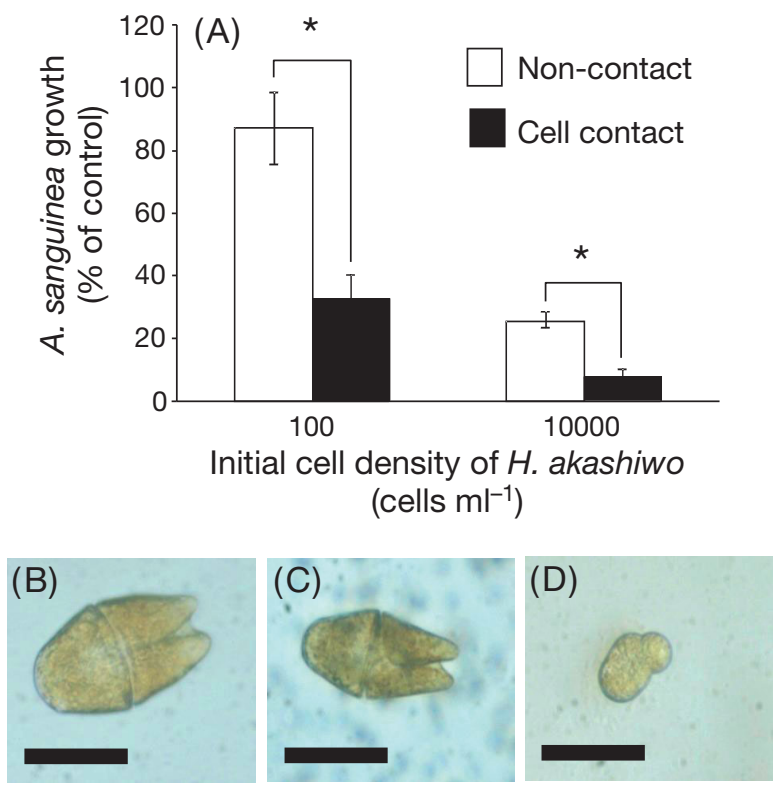

Fig. 6. Heterosigma akashiwo and Akashiwo sanguinea. Growth inhibitory effects in bi-algal cultures under noncontact and contact conditions. (A) Growth of A. sanguinea cultured together with $H$. akashiwo under non-contact and contact conditions. Means $\pm \mathrm{SD}(\mathrm{n}=3)$. *: significant difference between growth under non-contact and contact conditions $(\mathrm{p}<0.05)$. A. sanguinea cell (B) from mono-algal culture (control) and cultured together with $H$. akashiwo under (C) non-contact or (D) contact conditions. Scale bars $=50 \mu \mathrm{m}$ of A. sanguinea between mono-algal and bi-algal cultures under non-contact conditions (Table 3). However, in bi-algal cultures under contact conditions, many morphologically abnormal cells of $A$. sanguinea (Fig. 6D) appeared after Day 2 (initial density of $H$. akashiwo $1 \times 10^{4}$ cells ml ${ }^{-1}$ ) and 6 (initial density of $H$. akashiwo $1 \times 10^{2}$ cells ml ${ }^{-1}$ ), and the proportion of morphologically abnormal cells was significantly higher than that in mono-algal culture (Tukey test, p $<0.01$, Table 3) and in bi-algal cultures under non-contact conditions (Tukey test, $\mathrm{p}<0.01$, Table 3) on Day 8. There were no morphological changes in the cells of Heterosigma akashiwo through the experimental period (data not shown).

\section{Growth inhibitory effect of allelochemicals produced by Heterosigma akashiwo}

To determine whether APPCs produced by Heterosigma akashiwo (Yamasaki et al. 2009) affect growth of Akashiwo sanguinea, we examined growth inhibitory effects of the allelochemicals fraction prepared from culture filtrate of $H$. akashiwo. The growth of $A$. sanguinea was inhibited by allelochemicals in a concentration-dependent manner (Fig. 7A; Mann-Whitney $U$-test, p < 0.05). Furthermore, many morphologically abnormal cells appeared when $A$. sanguinea was exposed to concentrations of allelochemicals $>100 \mu \mathrm{g} \mathrm{ml}^{-1}$ (Fig. 7C).

Table 3. Heterosigma akashiwo and Akashiwo sanguinea. Initial cell densities of the 2 species and proportions of morphologically abnormal cells of $A$. sanguinea on Day 8 for bialgal culture experiments under non-contact and contact conditions. Data are mean \pm SD $(n=3)$. Different lower case superscripts indicate significantly different means (Tukey test, $\mathrm{p}<0.01$ )

\begin{tabular}{|c|c|c|}
\hline \multicolumn{2}{|c|}{$\begin{array}{l}\text { Initial cell density } \\
(\text { cells ml-1) }\end{array}$} & $\begin{array}{l}\text { Proportion of abnormal } \\
\text { A. sanguinea cells }\end{array}$ \\
\hline A. sanguinea & H. akashiwo & on Day 8 (\%) \\
\hline $\begin{array}{l}\text { Mono-algal cu } \\
1 \times 10^{2}\end{array}$ & ture & $3.60 \pm 0.92^{\mathrm{a}}$ \\
\hline $\begin{array}{l}\text { Non-contact } \\
1 \times 10^{2} \\
1 \times 10^{2}\end{array}$ & $\begin{array}{l}1 \times 10^{2} \\
1 \times 10^{4}\end{array}$ & $\begin{array}{l}5.54 \pm 1.24^{\mathrm{a}} \\
4.75 \pm 2.32^{\mathrm{a}}\end{array}$ \\
\hline $\begin{array}{l}\text { Cell contact } \\
1 \times 10^{2} \\
1 \times 10^{2}\end{array}$ & $\begin{array}{l}1 \times 10^{2} \\
1 \times 10^{4}\end{array}$ & $\begin{array}{l}22.60 \pm 5.03^{\mathrm{b}} \\
73.89 \pm 6.74^{\mathrm{c}}\end{array}$ \\
\hline
\end{tabular}



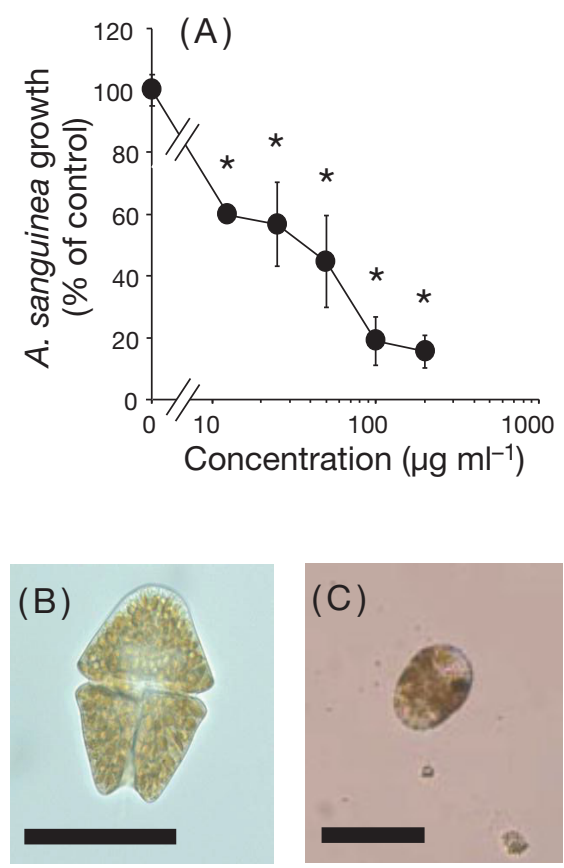

Fig. 7. Heterosigma akashiwo and Akashiwo sanguinea. Growth inhibitory effects of allelochemicals prepared from $H$. akashiwo culture medium filtrates. (A) Concentrationdependent growth inhibition of $A$. sanguinea by $H$. akashiwo allelochemicals. *: significant growth differences between exposed A. sanguinea and controls ( $p<0.01$ ). A. sanguinea cell (B) from mono-algal culture (control) and (C) exposed to allelochemicals. Scale bars $=50 \mu \mathrm{m}$

\section{DISCUSSION}

The physiological and ecological features of Heterosigma akashiwo and Akashiwo sanguinea suggest that both species have the potential to bloom during early summer (Honjo 1992, 1993, Smayda 1998, Matsubara et al. 2007). In reality, however, $H$. akashiwo often blooms, while $A$. sanguinea does not dominate in the field during that period. In the laboratory, we observed a strong growth inhibitory effect of $H$. akashiwo on $A$. sanguinea under the absence of various factors affecting phytoplankton growth such as grazing, turbulence, or nutrient limitation. Though further substantial research is required in the field, our results imply that $H$. akashiwo may have survival advantage over $A$. sanguinea through its growth inhibitory effects.

Previous studies demonstrated that nutrient limitation or elevation of $\mathrm{pH}$ values in media may affect growth interactions between phytoplankton (Hansen 2002, Fistarol et al. 2005). In the present bi-algal cultures, the concentrations of nitrogen $\left(\mathrm{NO}_{2}{ }^{-}+\mathrm{NO}_{3}{ }^{-}\right)$ and phosphorus $\left(\mathrm{PO}_{4}{ }^{3-}\right)$ decreased to $<2.78 \mu \mathrm{mol} \mathrm{l} \mathrm{l}^{-1}$ and $<4.42 \mu \mathrm{mol} \mathrm{l} \mathrm{l}^{-1}$, respectively, on Day 14, and media $\mathrm{pH}$ values ranged from 7.8 to 8.7 over the $14 \mathrm{~d}$ incubations (Table 1); that is, macronutrient concentration and $\mathrm{pH}$ value in mono-algal and bi-algal cultures were similar during the experiment. However, in bi-algal cultures growth of Akashiwo sanguinea was strongly suppressed immediately after the start of the experiments (Fig. 2), while in mono-algal cultures $A$. sanguinea was able to grow well when medium $\mathrm{pH}$ value reached $\sim 8.6$ (Table 1 ). Therefore, it seems that neither macronutrient limitation nor $\mathrm{pH}$ change in our culture media was a main factor inducing growth inhibitory effects of Heterosigma akashiwo on A. sanguinea.

The model obtained from the results of bi-algal cultures indicated that Heterosigma akashiwo, which has a much higher growth rate (Table 2), will always outcompete Akashiwo sanguinea over time because the estimated parameters show that $K_{x}<a K_{y}$ and $b K_{x}<K_{y}$ (Iwasa 1998). It can be concluded that $H$. akashiwo will always outcompete A. sanguinea because the trajectories of algal populations always converge on the point [(A. sanguinea, H. akashiwo $)=$ $\left.\left(0, K_{y}\right)\right]$ (Fig. 4) despite different combinations of their initial cell densities in bi-algal cultures. For example, in a case where initial cell densities of $H$. akashiwo and $A$. sanguinea are $1 \times 10^{2}$ and $2 \times 10^{3}$ cells ml $^{-1}$, respectively, cell densities of both $H$. akashiwo and $A$. sanguinea increase (Fig. 4, area I). Next, cell densities of $H$. akashiwo increase, but those of $A$. sanguinea decrease (Fig. 4, area II). Finally, cell densities of the 2 species converge on the point [(A. sanguinea, $H$. akashiwo $\left.)=\left(0, K_{y}\right)\right]$ (Fig. 4). Even though parameters used here for model predictions were derived from well-defined culture conditions (e.g. water temperature, light intensity, photoperiod, salinity, and artificially high nutrient levels), the growth inhibitory effect of $H$. akashiwo should be considered as a potentially important mechanism explaining the rarity of spring and early summer blooms of A. sanguinea in coastal waters of western Japan (Nakamura \& Hirata 2006, Tsutsumi 2006, Matsubara et al. 2008).

Though growth of Akashiwo sanguinea was inhibited by Heterosigma akashiwo via allelochemicals dissolved in the filtrate (Fig. 5), its effect was weaker than that in bi-algal culture experiments (lethal effects, see Fig. 2). Similar phenomena have been observed in previous studies (e.g. Wang \& Tang 2008, Tang \& Gobler 2010), and may be explained by lack of continuous supply of the allelochemicals (Fistarol et al. 2005) or effects of direct cell contact (Uchida 2001). Several recent studies, however, throw doubt on the significance of allelopathy in the 
field; that is, the relative importance of allelopathy in a species-rich ecological community may not be as high as predicted from laboratory studies (Suikkanen et al. 2005, Poulson et al. 2010). For example, A. sanguinea growth was inhibited by an extract of Karenia brevis cultures but not by waterborne compounds from $K$. brevis blooms (Prince et al. 2008, Poulson et al. 2010). Similarly, Jonsson et al. (2009) used simple models to analyze whether allelopathic effects may play a significant role under field conditions, and proposed that formation of HABs cannot be explained by allelopathy, whereas they pointed out the necessity to explore the presence of chemically mediated aggressive cell-cell interaction among phytoplankton. When growth inhibitory effects on $A$. sanguinea by $H$. akashiwo under conditions with and without cell contact were examined, effects of allelopathy and direct cell contact with $H$. akashiwo maximize growth inhibitory effects and induced formation of many morphologically abnormal cells in A. sanguinea (Fig. 6, Table 3). This suggests that compounds on the cell surface of $H$. akashiwo may play important roles in growth inhibition and formation of abnormal cells in A. sanguinea.

The exposure experiments using chemicals including APPCs produced by Heterosigma akashiwo suggested that allelopathic effects caused by APPCs strongly inhibited Akashiwo sanguinea growth (Fig. 7). Yamasaki et al. (2009) detected APPCs by dot-blot analysis of $H$. akashiwo cultures under axenic conditions at a density of $1 \times 10^{5}$ cells ml $^{-1}$. At this cell density, $H$. akashiwo can inhibit the growth of Skeletonema costatum (Yamasaki et al. 2007b). This supports the observed strong growth inhibitory effect on $A$. sanguinea when $H$. akashiwo reached high cell density in bi-algal cultures (Fig. 2). Furthermore, Yamasaki et al. (2009) reported that the concentration (estimated from dot-blot analysis) of APPCs dissolved in natural red-tide seawater was $\sim 40 \mu \mathrm{g} \mathrm{ml}^{-1}$, at which A. sanguinea growth was significantly inhibited (Fig. 6A). This is indicative of $H$. akashiwo APPCs being one important factor to inhibit $A$. sanguinea growth in the field. Yamasaki et al. (2009) reported that APPCs are present in the glycocalyx (Yokote et al. 1985) on H. akashiwo cell surfaces, and that their concentration dissolved in the media was $\sim 40 \mu \mathrm{g} \mathrm{ml}^{-1}$. In our study, only extremely high concentrations of allelochemicals including APPCs (>100 $\mathrm{g} \mathrm{m} \mathrm{m}^{-1}$ ) could induce the formation of many morphologically abnormal cells of A. sanguinea (Fig. 6). Furthermore, only a few morphologically abnormal cells of $A$. sanguinea occurred in bialgal cultures under non-contact conditions (allows continuous supply of the allelochemicals of $H$. akashiwo). Hence, direct cell contact with $H$. akashiwo, which allows $A$. sanguinea to contact more APPCs, is a requisite condition for the strong growth inhibitory effects on $A$. sanguinea associated with formation of many morphologically abnormal cells.

\section{CONCLUSIONS}

Heterosigma akashiwo may have a competitive advantage over Akashiwo sanguinea for bloom formation in the field. Both allelopathy and direct cell contact can induce growth inhibition effects of $H$. akashiwo on A. sanguinea. Though the molecular mechanism of growth inhibition is still unclear, the APPCs released into the media (i.e. allelopathy) and those existing on the cell surface of $H$. akashiwo (i.e. cell contact effects) may play important roles in the growth inhibition of $A$. sanguinea. Further studies with purified APPCs from $H$. akashiwo will clarify the molecular mechanism of growth inhibition of A. sanguinea by $H$. akashiwo, and further experiments in the natural environment (e.g. species-rich ecological community under oligotrophic conditions) should clarify its role in bloom formations in the field.

Acknowledgements. We thank Mie prefecture fisheries research institute for lending the 10-AU fluorometer (Turner Designs). This study was supported by funds from the Fisheries Agency of Japan.

\section{LITERATURE CITED}

Botes L, Smit AJ, Cook PA (2003) The potential threat of algal blooms to the abalone (Haliotis midae) mariculture industry situated around the South African coast. Harmful Algae 2:247-259

> Daugbjerg N, Hansen G, Larsen J, Moestrup Ø (2000) Phylogeny of some of the major genera of dinoflagellates based on ultrastructure and partial LSU rDNA sequence data, including the erection of three new genera of unarmoured dinoflagellates. Phycologia 39:302-317

> Domingos P, Menezes M (1998) Taxonomic remarks on planktonic phytoflagellates in a hypertrophic tropical lagoon (Brazil). Hydrobiologia 369/370:297-313

> Doucette GJ, Harrison PJ (1991) Aspects of iron and nitrogen nutrition in the red tide dinoflagellate Gymnodinium sanguineum. Mar Biol 110:175-182

> Fistarol GO, Legrand C, Granéli E (2005) Allelopathic effect on a nutrient-limited phytoplankton species. Aquat Microb Ecol 41:153-161

> Gómez F, Boicenco F (2004) An annotated checklist of dinoflagellates in the Black Sea. Hydrobiologia 517:43-59

Granéli E, Hansen PJ (2006) Allelopathy in harmful algae: a mechanism to compete for resources? In: Granéli E, Turner JT (eds) Ecology of harmful algae. Springer, 
Berlin, p 189-201

Guillard RRL (1973) Division rates. In: Stein JR (ed) Handbook of phycological methods: culture methods and growth measurements. Cambridge University Press, Cambridge, p 289-311

Hansen PJ (2002) Effect of high pH on the growth and survival of marine phytoplankton: implications for species succession. Aquat Microb Ecol 28:279-288

Honjo T (1992) Harmful red tides of Heterosigma akashiwo. NOAA Tech Rep NMFS 111:27-32

Honjo T (1993) Overview on bloom dynamics and physiological ecology of Heterosigma akashiwo. In: Smayda TJ, Shimizu Y (eds) Toxic Phytoplankton Blooms in the Sea. Elsevier, New York, NY, p 33-41

Iwasa Y (1998) Suri-seibutsugaku nyuumon, 2nd edn. Kyoritsu Syuppan, Tokyo

> Jessup DA, Miller MA, Ryan JP, Nevins HM and others (2009) Mass stranding of marine birds caused by a surfactant-producing red tide. PLoS ONE 4:e4450

$>$ Johansson M, Coats DW (2002) Ciliate grazing on the parasite Amoebophrya sp. decreases infection of the red-tide dinoflagellate Akashiwo sanguinea. Aquat Microb Ecol 28:69-78

Jonsson PR, Pavia H, Toth G (2009) Formation of harmful algal blooms cannot be explained by allelopathic interactions. Proc Natl Acad Sci USA 106:11177-11182

Kayser H (1979) Growth interactions between marine dinoflagellates in multispecies culture experiments. Mar Biol 52:357-369

Kim SH, Kim KY, Kim CH, Lee WS, Chang M, Lee JH (2004) Phylogenetic analysis of harmful algal bloom (HAB)causing dinoflagellates along the Korean coasts, based on SSU rRNA gene. J Microbiol Biotechnol 14:959-966

Kudela RM, Lane JQ, Cochlan WP (2008) The potential role of anthropogenically derived nitrogen in the growth of harmful algae in California, USA. Harmful Algae 8: 103-110

Laemmli UK (1970) Cleavage of structural proteins during the assembly of the head of bacteriophage T4. Nature 227:680-685

Lebour MV (1925) The dinoflagellates of northern seas. Mar Biol Assoc, Plymouth

Legrand C, Rengefors K, Fistarol GO, Granéli E (2003) Allelopathy in phytoplankton - biochemical, ecological and evolutionary aspects. Phycologia 42:406-419

Lu SH, Hodgkiss IJ (2004) Harmful algal bloom causative collected from Hong Kong waters. Hydrobiologia 512: 231-238

Marquardt DW (1963) An algorithm for least-squares estimation of nonlinear inequalities. SIAM J Appl Math 11: 431-441

Martin GW (1929) Dinoflagellates from marine and brackish waters of New Jersey. University of Iowa Studies in Natural History 12:1-32

> Matsubara T, Nagasoe S, Yamasaki Y, Shikata T, Shimasaki Y, Oshima Y, Honjo T (2007) Effects of temperature, salinity, and irradiance on the growth of the dinoflagellate Akashiwo sanguinea. J Exp Mar Biol Ecol 342:226-230

Matsubara T, Nagasoe S, Yamasaki Y, Shikata T, Shimasaki Y, Oshima Y, Honjo T (2008) Inhibitory effects of centric diatoms on the growth of the dinoflagellate Akashiwo sanguinea. Nippon Suisan Gakkai Shi 74:598-606 (in Japanese with English abstract)

Nakamura Y, Hirata A (2006) Plankton community structure and trophic interactions in a shallow and eutrophic estuarine system, Ariake Sound, Japan. Aquat Microb Ecol 44:45-57

Paul C, Barofsky A, Vidoudez C, Pohnert G (2009) Diatom exudates influence metabolism and cell growth of cocultured diatom species. Mar Ecol Prog Ser 389:61-70

Porter KG, Feig YS (1980) The use of DAPI for identifying and counting aquatic microflora. Limnol Oceanogr 25: 943-948

Poulson KL, Sieg RD, Kubanek J (2009) Chemical ecology of the marine phytoplankton. Nat Prod Rep 26:729-745

Poulson KL, Sieg RD, Prince EK, Kubanek J (2010) Allelopathic compounds of a red tide dinoflagellate have species-specific and context-dependent impacts on phytoplankton. Mar Ecol Prog Ser 416:69-78

Prince EK, Myers TL, Kubanek J (2008) Effects of harmful algal blooms on competitors: allelopathic mechanisms of the red tide dinoflagellate Karenia brevis. Limnol Oceanogr 53:531-541

- Rines JEB, McFarland MN, Donaghay PL, Sullivan JM (2010) Thin layers and species-specific characterization of the phytoplankton community in Monterey Bay, California, USA. Cont Shelf Res 30:66-88

> Silva ES, Faust MA (1995) Small cells in the life history of dinoflagellates (Dinophyceae): a review. Phycologia 34: 396-408

Smayda TJ (1998) Ecophysiology and bloom dynamics of Heterosigma akashiwo (Raphidophyceae). In: Anderson DM, Cembella AD, Hallegraeff GM (eds) Physiological Ecology of Harmful Algal Blooms. Springer, Berlin, p 113-131

Smayda TJ (2008) Complexity in the eutrophication-harmful algal bloom relationship, with comment on the importance of grazing. Harmful Algae 8:140-151

Suikkanen S, Fistarol GO, Granéli E (2005) Effects of cyanobacterial allelochemicals on a natural plankton community. Mar Ecol Prog Ser 287:1-9

> Tang YZ, Gobler CJ (2010) Allelopathic effects of Cochlodinium polykrikoides isolates and blooms from the estuaries of Long Island, New York, on co-occurring phytoplankton. Mar Ecol Prog Ser 406:19-31

Tezaki K, Iwataki M, Matsuoka K, Mizushima K (2005) Species composition and seasonal changes of phytoplankton occurred in Ariake Sound. Bull Fac Fish Nagasaki Univ 86:1-10

Tomas CR (ed) Hasle GR, Syvertsen EE, Steidinger KA, Tangen K, Throndsen J, Heimdal BR (contributors) (1997) Identifying marine phytoplankton. Academic Press, San Diego, CA

Tsutsumi H (2006) Critical events in the Ariake Bay ecosystem: Clam population collapse, red tides, and hypoxic bottom water. Plankton Benthos Res 1:3-25

Uchida T (2001) The role of cell contact in the life cycle of some dinoflagellate species. J Plankton Res 23:889-891

Uchida T, Toda S, Matsuyama Y, Yamaguchi M, Kotani Y, Honjo $T$ (1999) Interactions between the red tide dinoflagellates Heterocapsa circularisquama and Gymnodinium mikimotoi in laboratory culture. J Exp Mar Biol Ecol 241:285-299

Voltolina D (1993) The origin of recurrent blooms of Gymnodinium sanguineum Hirasaka in a shallow coastal lagoon. J Exp Mar Biol Ecol 168:217-222

Wang Y, Tang X (2008) Interactions between Prorocentrum donghaiense $\mathrm{Lu}$ and Scrippsiella trochoidea (Stein) Loeblich III under laboratory culture. Harmful Algae 7: 65-75 
Yamasaki Y, Nagasoe S, Matsubara T, Shikata T, Shimasaki Y, Oshima Y, Honjo T (2007a) Growth inhibition and formation of morphologically abnormal cells of Akashiwo sanguinea (Hirasaka) G. Hansen et Moestrup by cell contact with Cochlodinium polykrikoides Margalef. Mar Biol 152:157-163

Yamasaki Y, Nagasoe S, Matsubara T, Shikata T, Shimasaki Y, Oshima Y, Honjo T (2007b) Allelopathic interactions between the bacillariophyte Skeletonema costatum and the raphidophyte Heterosigma akashiwo. Mar Ecol Prog Ser 339:83-92

Yamasaki Y, Shikata T, Nukata A, Ichiki S and others

Editorial responsibility: Hans Heinrich Janssen, Oldendorf/Luhe, Germany
(2009) Extracellular polysaccharide-protein complexes of a harmful alga mediate the allelopathic control it exerts within the phytoplankton community. ISME J 3: 808-817

Yamatogi T, Sakaguchi M, Iwataki M, Matsuoka K (2006) Effects of temperature and salinity on the growth of four harmful red tide flagellates occurring in Isahaya Bay in Ariake Sound, Japan. Nippon Suisan Gakkai Shi 72: 160-168 (in Japanese with English abstract)

Yokote M, Honjo T, Asakawa M (1985) Histochemical demonstration of a glycocalyx on the cell surface of Heterosigma akashiwo. Mar Biol 88:295-299

Submitted: April 27, 2011; Accepted: November 2, 2011 Proofs received from author(s): January 24, 2012 